\title{
Safety and Efficacy of Bivalirudin in Diabetic Acute Coronary Syndrome (ACS) Patients Undergoing Percutaneous Coronary Intervention (PCI)
}

\author{
A. B. M. Golam Mostofa, Tanjima Parvin, Mohammad Rayhan Masum Mandal, Rawnak Afrin, \\ Manzoor Mahmood, and Syed Ali Ahsan
}

ABSTRACT

Objective: To determine and compare the incidence of in-hospital and 30day hemorrhagic complications and major adverse cardiac events (MACEs) as evidence of safety and efficacy using Bivalirudin versus Heparin in diabetic acute coronary syndrome (ACS) patients undergoing percutaneous coronary intervention (PCI) in a tertiary care cardiac hospital.

Background: Prevention of hemorrhagic complications has emerged as a priority in patients undergoing PCI in addition to suppressing thrombotic complications. This goal is challenging to achieve in diabetic ACS patients as DM itself is a prothrombotic state with more pronounced vascular injury response and have a worse outcome after PCI compared with non-diabetic patients. In patients with ACS, Bivalirudin has been shown to result in similar rates of composite ischemia as Heparin plus GPI (GP IIb /IIIa inhibitor), while significantly reducing major bleeding and has received class I recommendation for PCI. Whether Bivalirudin is safe and effective in diabetic ACS patients undergoing PCI, as compared with Heparin (UFH) monotherapy, is unknown.

Methods: 218 diabetic ACS patients (age $>18$ years and $\leq 75$ years) who underwent PCI from May 2018 to April 2019 at UCC, BSMMU, Dhaka, Bangladesh were randomly assigned to have UFH or Bivalirudin. Before the guide wire crossed the lesion, 111 patients in the UFH group received a bolus of 70-100 U/kg (targeted activated clotting time, ACT: 200-250 s). 107 patients in the Bivalirudin group received a loading dose of $0.75 \mathrm{mg} / \mathrm{kg}$, followed by an infusion of $1.75 \mathrm{mg} / \mathrm{kg} / \mathrm{h}$ for up to 4 hours. Dual antiplatelet (DAPT) loading as Aspirin $300 \mathrm{mg}$ plus P2Y12 inhibitors (Clopidogrel $600 \mathrm{mg}$ or Prasugrel $60 \mathrm{mg}$ or Ticagrelor $180 \mathrm{mg}$ ) was given in all patients before the procedure. The maintenance dose of DAPT was continued for at least one month and patients were followed telephonically up to 30 days. The outcome measures were in-hospital and 30-day hemorrhagic complications and MACEs [death, MI, target vessel revascularization (TVR) and stroke].

Results: Patients treated with Bivalirudin compared with Heparin had a significantly lower in-hospital incidence of QMI $(0 \%$ vs. 6\%; $\mathrm{p}=0.03)$ and major bleeding $(0 \%$ vs. $7 \%$; $p=0.02)$. However, the incidence of cardiac death, stent thrombosis, TVR were no differences between the groups $(p>0.05)$. There was only one NQMI in the Bivalirudin group as opposed to $8 \%$ in the Heparin group in 30 days following stenting $(p=0.04)$. No other adverse effects were found significantly different between groups in $\mathbf{3 0}$ days of PCI.

Conclusion: In this small scale, prospective, randomized controlled study of diabetic ACS patients undergoing PCI in a single center showed that Bivalirudin is safe and effective as it reduces immediate and short-term hemorrhagic complications as well as MACEs as compared with Heparin.

Keywords: ACS (Acute Coronary Syndrome), Bivalirudin, DM (Diabetes Mellitus), PCI (Percutaneous coronary intervention).

Submitted : March 1, 2021

Published : April 02, 2021

ISSN: $2593-8339$

DOI: $10.24018 /$ ejmed.2021.3.2.768

Dr A. B. M. Golam Mostofa

Resident, Department of Cardiology,

University Cardiac Center (UCC),

Bangabandhu Sheikh Mujib Medical

University (BSMMU), Dhaka,

Bangladesh.

(e-mail: drmostofabd@gmail.com)

Dr Tanjima Parvin

Associate Professor, Department of Cardiology, UCC, BSMMU, Dhaka, Bangladesh.

Dr Mohammad Rayhan Masum Mandal

Assistant Professor, Department of Cardiology, UCC, BSMMU, Dhaka, Bangladesh.

Dr Rawnak Afrin

Associate Professor, Institute of Nuclear Medicine \& Allied Sciences, Dhaka Medical College Hospital, Dhaka, Bangladesh.

Professor Manzoor Mahmood

Department of Cardiology, University Cardiac Center (UCC), BSMMU, Dhaka, Bangladesh.

Professor Syed Ali Ahsan

Chairman, and Head, Division of Interventional Cardiology, UCC, BSMMU, Dhaka, Bangladesh.

*Corresponding Author 


\section{INTRODUCTION}

Acute coronary syndromes (ACS) represent the principal form of clinical presentation of coronary artery disease (CAD) [1]. CAD is a growing epidemic in South Asia and is the leading cause of mortality in the Indian subcontinent [2], as well as Bangladesh [3]. In Bangladesh, approximately 27\% of CAD patients are diabetic [3].

Coronary artery plaque rupture initiates ACS by activating the platelet as well as coagulation cascade and thrombin plays a pivotal role in thrombus formation [4]. Effective and timely reperfusion of the infarct-related coronary artery is central to optimal treatment for both STEMI and NSTE-ACS and as expeditiously and efficiently achieved by the PCI [5]. Anticoagulant (UFH or Bivalirudin) in combination with antiplatelet (aspirin, $\mathrm{P}_{2} \mathrm{Y}_{12}$ inhibitors, with or without GPI), is most commonly used adjunctive antithrombotic regimen worldwide to improve angiographic and clinical outcomes in a patient undergoing PCI [6]. Prevention of hemorrhagic complications has emerged as a priority in patients undergoing PCI in addition to suppressing thrombotic complications [7]. This goal is challenging to achieve in diabetic ACS patients as DM itself is a pro-inflammatory and prothrombotic state with enhanced thrombin generation, platelet reactivation, more pronounced vascular injury response and generally have a worse outcome after PCI compared with non-diabetic patients [8], [9].

Identification of most appropriate adjunctive antithrombotic therapy before, during, and after PCI has been the target of extensive research for the past three decades [10].

UFH is traditionally regarded as the standard anticoagulant strategy during PCI though it has an intrinsic limitation. UFH cannot inhibit thrombin without antithrombin-III or heparin cofactor-II. UFH binds to vWF, several plasma proteins, endothelial cells, and macrophages, which reduces its anticoagulant activity, leads to heparin resistance. Relatively rapid clearance of UFH produces a heparin rebound effect i.e., increased thrombin activity within a few hours after its cessation. So, UFH may cause heparin-induced thrombocytopenia (HIT), unpredictable pharmacokinetics, a non-linear anticoagulant response concerning peak effect and duration of action, a highly variable dose-response relation, resulting in a narrow therapeutic window [11]-[15]. To overcome these limitations GPI invariably uses with heparin during PCI which is costly and increases the risk of bleeding [16].

Bivalirudin is a 20 amino acid polypeptide and is a reversible direct thrombin inhibitor. It inhibits both circulating and clot bound thrombin as well as thrombin mediated platelet activation. It has linear pharmacokinetics and short half-life ( $\sim 25 \mathrm{~min})$ and lab monitoring of efficacy are not required [15]. Randomized clinical trials and various meta-analyses have shown that bivalirudin significantly reduces bleeding-related complications in patients undergoing PCI [6], [8], [17]-[20]. Based on this evidence, Bivalirudin $(0.75 \mathrm{mg} / \mathrm{kg} \mathrm{I} / \mathrm{V}$ bolus, followed by $1.75 \mathrm{mg} / \mathrm{kg} / \mathrm{h}$ for up to $4 \mathrm{~h}$ after the procedure) is recommended as an alternative to UFH plus GPI during PCI in both STEMI [21] and NSTE-ACS [22]. However, previous studies that have compared heparin, heparin plus GPI and bivalirudin yielded contradictory results concerning ischemic, bleeding, or combined outcomes [23], [24]. Whether Bivalirudin is safe and effective in diabetic ACS patients undergoing PCI, as compared with Heparin monotherapy is unknown.

In the current study, we tried to determine and compare the incidence of in-hospital and 30 days hemorrhagic complications as well as MACEs using Bivalirudin versus Heparin in diabetic ACS patients who underwent PCI in a tertiary care hospital to evaluate safety and efficacy of bivalirudin.

\section{METHOD}

\section{A. Study Population}

In this randomized controlled study, 218 diabetic ACS patients (age $>18$ years and $\leq 75$ years) who underwent $\mathrm{PCI}$ from May 2018 to April 2019 at UCC, BSMMU, Dhaka were enrolled after exclusion of following criteria: patients with the chronic coronary syndrome, prior MI, prior revascularization, mechanical complication, prior thrombolytic within 8 hours, current use of warfarin, history of bleeding diathesis or known coagulopathy (including HIT), history of intracerebral mass, aneurysm, AVM, stroke within 6 months or any permanent neurologic deficit; GI or GU bleeding within 2 months, or major surgery within 6 weeks; recent or known platelet count $<100,000$ cells $/ \mathrm{mm}^{3}$ or hemoglobin $<10 \mathrm{~g} / \mathrm{dL}, \mathrm{Cr} \mathrm{Cl}<30 \mathrm{ml} / \mathrm{min}$. The study was approved by the institutional ethical committee and all patients gave written informed consent.

\section{B. Study Protocol}

DAPT loading as Aspirin $300 \mathrm{mg}$ plus $\mathrm{P}_{2} \mathrm{Y}_{12}$ inhibitors (Clopidogrel $600 \mathrm{mg}$ or Prasugrel $60 \mathrm{mg}$ or Ticagrelor $180 \mathrm{mg}$ ) was given in all patients at least 2 hours before PCI. The transfemoral approach for coronary angiography was undertaken by using a modified Seldinger technique with a $7 \mathrm{~F}$ introducer sheath. After the decision had been made to perform a coronary intervention, 218 patients were randomly assigned, in an open-label fashion to treatment with UFH or Bivalirudin. Before the guide wire crossed the lesion, 111 patients in the UFH group received a bolus of 70-100 U/kg (targeted ACT: 200-250 s). 107 patients in the Bivalirudin group received a loading dose of $0.75 \mathrm{mg} / \mathrm{kg}$, followed by an infusion of $1.75 \mathrm{mg} / \mathrm{kg} / \mathrm{h}$ for up to 4 hours. If UFH was administered in a patient in the bivalirudin group, bivalirudin was started $30 \mathrm{~min}$ later but in all cases before PCI. Coronary stenting with drug-eluting stent was performed according to the discretion of the operator and caregiver's choice. Stent apposition was good. Less than $30 \%$ residual stenosis after the procedure was counted as successful PCI. Sheaths were removed and manual compression was applied as soon as the ACT fell below $150 \mathrm{~s}$. The patients were mobilized after $6 \mathrm{~h}$ of sheath removal and were typically discharged from the hospital 24-48 $\mathrm{h}$ after the procedure. All patients were followed up over telephone or OPD consultation up to 30 days to determine hemorrhagic complications and MACEs.

\section{Study Endpoints}

The outcome measures were in-hospital and 30-day hemorrhagic complications \& MACEs. The definition of major bleeding was based on (REPLACE-2) trial and 
included intracranial, intraocular, or retroperitoneal hemorrhage; clinically overt blood loss resulting in a decrease in hemoglobin of more than $3 \mathrm{~g} / \mathrm{dl}$, any decrease in hemoglobin of more than $4 \mathrm{~g} / \mathrm{dl}$; or transfusion of 2 or more units of packed red cells or whole blood [6]. Recurrent MI was defined in the presence of both ischemic pain and a new $>50 \%$ increase in Troponin I level. The MI definitions were adapted from the Joint European Society of Cardiology/American College of Cardiology Committee statement on the universal definition of MI [25]. Cardiac Death was defined as death due to acute MI, cardiac perforation, pericardial tamponade, arrhythmia or conduction abnormality, stroke, procedural complications, or any death for which a cardiac cause could not be ruled out. Stent thrombosis was defined according to the Academic Research Consortium (ARC) classification [26].

\section{Statistical Analysis}

Statistical analyses were conducted using the Statistical Package for Social Science (SPSS) version 23.0 windows software. Parametric data were expressed in mean \pm SD and analyzed by Student's t-test. Categorical data were expressed as frequencies \& percentages and analyzed by Chi-Square test. The level of significance for all analytical tests was set at 0.05 and p-value less than 0.05 is considered significant.

\section{RESULTS}

The present study, intended to evaluate the safety and efficacy of bivalirudin in PCI, included a total of 218 diabetic ACS patients, who underwent PCI were randomly assigned to treatment with bivalirudin (107 patients) or UFH (111 patients). Among them, 7 patients in bivalirudin and 11 patients in the heparin arm had lost to follow up. So, finally, a total of 100 patients were in each group. The outcome measures were in-hospital and 30-day morbidity (complications or adverse events) and mortality. The findings of the study obtained from data analyses are documented below:
TABLE II: CLINICAL PRESENTATION AND MEDICATIONS AT BASELINE

\begin{tabular}{|c|c|c|c|}
\hline Characteristic & $\begin{array}{c}\text { Bivalirudin } \\
(\mathrm{n}=100)\end{array}$ & $\begin{array}{l}\text { Heparin (UFH) } \\
(\mathrm{n}=100)\end{array}$ & P-value \\
\hline Clinical presentation & & & \\
\hline $\begin{array}{c}\text { ST-segment elevation } \\
\text { myocardial infarction, } \mathrm{n}(\%)\end{array}$ & $69(69.0)$ & $63(63.0)$ & ${ }^{\mathrm{b}} 0.370^{\mathrm{ns}}$ \\
\hline $\begin{array}{l}\text { Non-ST-segment elevation } \\
\text { myocardial infarction, } \mathrm{n}(\%)\end{array}$ & $27(27.0)$ & $26(26.0)$ & ${ }^{\mathrm{b}} 0.872^{\mathrm{ns}}$ \\
\hline Unstable angina, $\mathrm{n}(\%)$ & $4(4.0)$ & $11(11.0)$ & ${ }^{\mathrm{b}} 0.060^{\mathrm{ns}}$ \\
\hline $\begin{array}{l}\text { Systolic arterial pressure, } \\
(\mathrm{mmHg})\end{array}$ & $126.55 \pm 13.5$ & $125.75 \pm 14.6$ & ${ }^{\mathrm{a}} 0.688^{\mathrm{ns}}$ \\
\hline Heart rate (beats/min) & $67.01 \pm 5.8$ & $65.32 \pm 7.2$ & ${ }^{\mathrm{a}} 0.070^{\mathrm{ns}}$ \\
\hline $\begin{array}{l}\text { Left ventricular ejection } \\
\text { fraction, } \mathrm{LVEF} \geq 40 \%, \mathrm{n} \\
\qquad(\%)\end{array}$ & $88(88.0)$ & $81(81.0)$ & ${ }^{\mathrm{b}} 0.171^{\mathrm{ns}}$ \\
\hline $\begin{array}{l}\text { CKMB /Troponin I } \\
\text { Elevated, } \mathrm{n}(\%)\end{array}$ & $96(96.0)$ & $89(89.0)$ & ${ }^{\mathrm{b}} 0.060^{\mathrm{ns}}$ \\
\hline HbA1c $(\%)$ & $9.79 \pm 1.9$ & $9.53 \pm 1.9$ & ${ }^{\mathrm{a}} 0.349^{\mathrm{ns}}$ \\
\hline $\begin{array}{c}\text { Premedication with DAPT, } \\
\text { no. }(\%)\end{array}$ & & & \\
\hline Aspirin + Ticagrelor, n (\%) & $89(89.0)$ & $90(90.0)$ & ${ }^{\mathrm{b}} 1.000^{\mathrm{ns}}$ \\
\hline Aspirin + Clopidogrel, $\mathrm{n}(\%)$ & $1(1.0)$ & $6(6.0)$ & ${ }^{\mathrm{b}} 0.123^{\mathrm{ns}}$ \\
\hline Aspirin + Prasugrel, n (\%) & $10(10.0)$ & $4(4.0)$ & ${ }^{\mathrm{b}} 0.096^{\mathrm{ns}}$ \\
\hline
\end{tabular}

ns $=$ not significant, $a=P$ value reached from unpaired $t$-test, $b=P$ value reached from Chi-square test.

TABLE III: ANGIOGRAPHIC AND PROCEDURAL CHARACTERISTICS

\begin{tabular}{cccc}
\hline Characteristic & $\begin{array}{c}\text { Bivalirudin } \\
(\mathrm{n}=100)\end{array}$ & $\begin{array}{c}\text { Heparin (UFH) } \\
(\mathrm{n}=100)\end{array}$ & P-value \\
\hline Femoral approach, $\mathrm{n}(\%)$ & $100(100.0)$ & $100(100.0)$ & - \\
Severity of disease & & & \\
Single vessel disease, $\mathrm{n}(\%)$ & $42(42.0)$ & $47(47.0)$ & $\mathrm{b} 0.569 \mathrm{~ns}$ \\
Double vessel disease, $\mathrm{n}(\%)$ & $45(45.0)$ & $33(33.0)$ & $\mathrm{b} 0.082 \mathrm{~ns}$ \\
Triple vessel disease, $\mathrm{n}(\%)$ & $13(13.0)$ & $20(20.0)$ & $\mathrm{b} 0.253 \mathrm{~ns}$ \\
Lesion characteristics & & & \\
Type-A, $\mathrm{n}(\%)$ & $53(53.0)$ & $47(47.0)$ & $\mathrm{b} 0.396 \mathrm{~ns}$ \\
Type-B, $\mathrm{n}(\%)$ & $41(41.0)$ & $46(46.0)$ & $\mathrm{b} 0.476 \mathrm{~ns}$ \\
Type-C, $\mathrm{n}(\%)$ & $6(6.0)$ & $7(7.0)$ & $\mathrm{b} 0.774 \mathrm{~ns}$ \\
Procedural Characteristics & & & \\
Number of treated lesions & $1.78 \pm 0.76$ & $1.74 \pm .0 .76$ & $\mathrm{a} 0.710 \mathrm{~ns}$ \\
per patient & $1.61 \pm 0.7$ & $1.67 \pm 0.8$ & $\mathrm{a} 0.592 \mathrm{~ns}$ \\
Number of stents per patient & $64(64.0)$ & $66(66.0)$ & $\mathrm{b} 0.766 \mathrm{~ns}$ \\
Intervention on LAD, $\mathrm{n}(\%)$ & $42(42.0)$ & $44(44.0)$ & $\mathrm{b} 0.775 \mathrm{~ns}$ \\
Intervention on RCA, $\mathrm{n}(\%)$ & $31(31.0)$ & $37(37.0)$ & $\mathrm{b} 0.370 \mathrm{~ns}$ \\
Intervention on LCX, $\mathrm{n}(\%)$ & $100(100.0)$ & $100(100.0)$ & - \\
Use of drug-eluting stent, & & & \\
n (\%) & $26.42 \pm 5.2$ & $25.55 \pm 6.3$ & $\mathrm{a} 0.292 \mathrm{~ns}$ \\
Stent length (mm), mean & $2.94 \pm 0.3$ & $2.90 \pm 0.3$ & $\mathrm{a} 0.274 \mathrm{~ns}$ \\
Stent diameter (mm) & & &
\end{tabular}

TABLE IV: IN-HOSPITAL CLINICAL OUTCOME

\begin{tabular}{|c|c|c|c|}
\hline Outcome & $\begin{array}{l}\text { Bivalirudin } \\
(\mathrm{n}=100)\end{array}$ & $\begin{array}{c}\text { Heparin (UFH) } \\
(\mathrm{n}=100)\end{array}$ & P-value \\
\hline \multicolumn{4}{|l|}{ Efficacy endpoint (MACEs) } \\
\hline Cardiac death, n (\%) & $1(1.0)$ & $4(4.0)$ & $0.366 \mathrm{~ns}$ \\
\hline QMI, n (\%) & $0(0.0)$ & $6(6.0)$ & $0.038 \mathrm{~s}$ \\
\hline Non-QMI, n (\%) & $1(1.0)$ & $2(2.0)$ & $1.00 \mathrm{~s}$ \\
\hline $\begin{array}{l}\text { Urgent target vessel } \\
\text { revascularization, } \mathrm{n}(\%)\end{array}$ & $0(0.0)$ & $2(2.0)$ & $0.477 \mathrm{~ns}$ \\
\hline Stent thrombosis, n (\%) & $0(0.0)$ & $2(2.0)$ & $0.477 \mathrm{~ns}$ \\
\hline \multicolumn{4}{|c|}{$\begin{array}{c}\text { Safety endpoints (hemorrhagic } \\
\text { events) }\end{array}$} \\
\hline Major bleeding, n (\%) & $0(0.0)$ & $7(7.0)$ & $0.021 \mathrm{~s}$ \\
\hline Minor bleeding, n (\%) & $1(1.0)$ & $3(3.0)$ & $0.607 \mathrm{~s}$ \\
\hline $\begin{array}{l}\text { Vascular access site } \\
\text { complication, } \mathrm{n}(\%)\end{array}$ & $1(1.0)$ & $1(1.0)$ & $0.478 \mathrm{~ns}$ \\
\hline
\end{tabular}

\begin{tabular}{cccc}
\multicolumn{4}{c}{ TABLE I: CHARACTERISTICS OF THE PATIENTS AT BASELINE } \\
\hline Characteristic & $\begin{array}{c}\text { Bivalirudin } \\
(\mathrm{n}=100)\end{array}$ & $\begin{array}{c}\text { Heparin } \\
(\text { UFH }) \\
(\mathrm{n}=100)\end{array}$ & P-value \\
\hline Age (years) & $53.49 \pm 9.9$ & $52.99 \pm 8.9$ & ${ }^{\mathrm{a}} 0.710^{\mathrm{ns}}$ \\
Male sex, $\mathrm{n}(\%)$ & $90(90.0)$ & $81(81.0)$ & ${ }^{\mathrm{b}} 0.070^{\mathrm{ns}}$ \\
BMI $\left(\mathrm{kg} / \mathrm{m}^{2}\right)$ & $24.21 \pm 2.7$ & $23.82 \pm 2.8$ & ${ }^{\mathrm{a}} 0.317^{\mathrm{ns}}$ \\
Hypertension, $\mathrm{n}(\%)$ & $69(69.0)$ & $64(64.0)$ & ${ }^{\mathrm{b}} 0.453^{\mathrm{ns}}$ \\
Dyslipidemia, $\mathrm{n}(\%)$ & $65(65.0)$ & $58(58.0)$ & ${ }^{\mathrm{b}} 0.069^{\mathrm{ns}}$ \\
Current smoker, $\mathrm{n}(\%)$ & $48(48.0)$ & $46(46.0)$ & ${ }^{\mathrm{b}} 0.776^{\mathrm{ns}}$ \\
Renal insufficiency, $* \mathrm{n}(\%)$ & $4(4.0)$ & $3(3.0)$ & ${ }^{\mathrm{b}} 0.700^{\mathrm{ns}}$ \\
Family history of coronary artery & $12(12.0)$ & $19(19.0)$ & ${ }^{\mathrm{b}} 0.171^{\mathrm{ns}}$ \\
disease, $\mathrm{n}(\%)$ & $29(29.0)$ & $23(23.0)$ & ${ }^{\mathrm{b}} 0.420^{\mathrm{ns}}$ \\
Previous Myocardial infarction & & & \\
(MI), $\mathrm{n}(\%)$ & $3(3.0)$ & $1(1.0)$ & ${ }^{\mathrm{b}} 0.613^{\mathrm{ns}}$ \\
Previous coronary intervention, & $2(2.0)$ & $1(1.0)$ & ${ }^{\mathrm{b}} 0.561^{\mathrm{ns}}$ \\
$\mathrm{n}(\%)$ & $1(1.0)$ & $1(1.0)$ & ${ }^{\mathrm{b}} 0.477^{\mathrm{ns}}$ \\
\hline Previous stroke, $\mathrm{n}(\%)$ & & &
\end{tabular}

\begin{tabular}{cccc}
\multicolumn{4}{c}{ TABLE V: CliniCAL OUTCOME OF UP TO 30 DAYS } \\
\hline Outcome & $\begin{array}{c}\text { Bivalirudin } \\
(\mathrm{n}=100)\end{array}$ & $\begin{array}{c}\text { Heparin (UFH) } \\
(\mathrm{n}=100)\end{array}$ & P-value \\
\hline Cardiac death, n (\%) & $0(0.0)$ & $1(1.0)$ & $1.00 \mathrm{~ns}$ \\
QMI, n (\%) & $1(1.0)$ & $2(2.0)$ & $1.00 \mathrm{~ns}$ \\
Non-QMI, n (\%) & $1(1.0)$ & $8(8.0)$ & $0.040 \mathrm{~s}$ \\
$\begin{array}{c}\text { Urgent target vessel } \\
\text { revascularization, n (\%) }\end{array}$ & $0(0.0)$ & $2(2.0)$ & $0.477 \mathrm{~ns}$ \\
$\begin{array}{c}\text { Stent thrombosis, n (\%) } \\
\text { Vascular access site }\end{array}$ & $0(0.0)$ & $2(2.0)$ & $0.477 \mathrm{~ns}$ \\
complication, n (\%) & $1(1.0)$ & $0(0.0)$ & $1.00 \mathrm{~ns}$ \\
\hline
\end{tabular}




\section{A. Patients and Procedure}

The baseline demographic, clinical and procedural characteristics were well balanced between treatment groups. Mean age and sex were statistically similar between the bivalirudin and heparin group $(\mathrm{p}=0.710$ and $\mathrm{p}=0.070$ respectively). The mean age of the former and the latter groups was $53.49 \pm 9.9$ years and $52.99 \pm 8.9$ years respectively. A male predominance was observed in either group. Distribution of risk factors like hypertension, dyslipidemia, smoking was almost identical between the study group ( $\mathrm{p}=0.453, \mathrm{p}=0069$ and $\mathrm{p}=0.776$ respectively). (Table I).

Majority of the patients in each group present with STEMI $(\mathrm{p}=0.370)$ and received DAPT in the form of Aspirin plus Ticagrelor $(\mathrm{p}=1.00)$. Distribution of blood pressure, LVEF, HbA1C were almost identical between the study group (P>0.05) (Table II).

Bivalirudin arm had less SVD (42\%) than heparin (47\%) and more DVD (45\%) than heparin (33\%) but it did not reach statistical significance $(\mathrm{p}=0.569 \& \mathrm{p}=0.082$ respectively). In terms of lesion characteristics as well, the groups were almost homogeneous with Type-A lesion being higher in either group ( $p=0.396$ ). LAD followed by RCA PCI was common in each group. Distribution of the number of treated lesions per patient, number of stents per patient, stent length and width were similar between study group ( $\mathrm{p}>0.05)$ (Table III).

\section{B. Clinical Outcomes (in-hospital)}

In this study, the patients treated with bivalirudin compared with those treated with heparin had a significantly lower incidence of QMI lesions (0\% vs. 6\%; p=0.04) and major bleeding ( $0 \%$ vs. $7 \%$; $=0.02)$. However, the incidence of cardiac death, stent thrombosis, urgent target vessel revascularization was no difference between the groups ( $\mathrm{p}=0.366, \mathrm{p}=0.477$ and $\mathrm{p}=0.477$ respectively) (Table IV).

\section{Clinical Outcomes (at 30 days)}

There was only one NQMI in the bivalirudin group as opposed to $8 \%$ in the heparin group in 30 days following stenting $(\mathrm{p}=0.04)$. No other adverse effects were found significantly different between groups in 30 days of PCI (Table V).

\section{DISCUSSION}

In this prospective, randomized controlled study involving diabetic ACS patients who were undergoing PCI, treatment with bivalirudin as compared with treatment with heparin, improved event-free survival at 30 days, owing to a significant reduction in major bleeding and reinfarction (QMI and NQMI). Cardiac death rate was less in bivalirudin arm as compared with heparin arm. There was no incidence of stent thrombosis and UTVR at all in the bivalirudin group as opposed to $4 \%$ in the heparin group up to 30 days of PCI.

\section{A. In Terms of the Safety Endpoint (Bleeding Risk)}

In terms of the safety endpoint (bleeding risk) our study findings are consistent with literature [11]. In an Indian study, Kaul et al. found that major bleeding was $1.59 \%$ in bivalirudin and $5.97 \%$ in heparin arm $(p<0.005)$ [27]. In a meta-analysis, Zhang et al. have reported that bivalirudin decreases the risk of major bleeding more significantly than heparin (174 DM patients in bivalirudin vs. 297 DM patients in heparin group experienced major bleeding: RR 0.63; $95 \%$ CI 0.52-0.75; $\mathrm{P}<0.00001$ ) [8]. Nairooz et al. concluded that bivalirudin reduces major bleeding risk significantly in diabetic ACS patients following PCI (OR 0.68; 95\% CI 0.52$0.89 ; \mathrm{P}=0.005)[20]$. Feit et al. have reported that major bleeding was $3.7 \%$ in bivalirudin arm and $7.1 \%$ in Heparin+GPI arm $(\mathrm{p}<0.001)$ [28]. Though, these results are contrary to the results of HEAT-PPCI study that suggested bleeding rates of heparin alone are not different from those of bivalirudin [23].

\section{B. In Terms of the Efficacy Endpoint (Major Adverse Cardiac Events)}

In terms of the efficacy endpoint (major adverse cardiac events) our study findings are also comparable to several clinical trials. Feit et al. have reported that QMI was $0.8 \%$ in bivalirudin arm and $1.6 \%$ in Heparin+GPI arm $(\mathrm{p}=0.05)$ but NQMI was $3.9 \%$ in bivalirudin arm and $4 \%$ in Heparin+GPI $\operatorname{arm}(\mathrm{p}=0.87)$ [28]. Witzenbichler et al. reported that QMI was $1.8 \%$ in bivalirudin arm and $2.3 \%$ in Heparin+GPI arm $(\mathrm{p}=0.69)$ whereas NQMI was $0.4 \%$ in bivalirudin arm and $1 \%$ in Heparin+GPI arm $(p=0.37)$ in 30 days of PCI [29]. The difference in protocols and operative definitions of post PCI MI and routine use of GPI with heparin is the reason for a little dissimilarity from our results [9], [29], [30].

In our study, there was no incidence of stent thrombosis and UTVR at all in the bivalirudin group as opposed to $2 \%$ in the heparin group (both in in-hospital and in 30 days following stenting). Kaul et al. has reported no incidence of stent thrombosis and UTVR in the bivalirudin group in 30 days of PCI which is consistent with our study [27]. A recent study from China BRIGHT using bivalirudin protocol similar to our study also did not show any increase in in-stent thrombosis while maintaining lower bleeding rates [19]. However, in the MATRIX, HORIZONS-AMI and EUROMAX trial, patients treated with bivalirudin were at higher risk for acute stent thrombosis, an observation inconsistent with the results of our study [24], [29], [30]. The increased risk for acute stent thrombosis was limited to the first $4 \mathrm{~h}$ after the index procedure and was probably the result of the combination of the short half-life and rapid clearance of bivalirudin and the delayed bioavailability of the oral P2Y12 inhibitors, including the newer agents Prasugrel and Ticagrelor. Another reason for higher stent thrombosis in the EUROMAX study was the lower dose of bivalirudin infusion $(0.25 \mathrm{mg} / \mathrm{kg} / \mathrm{hour})$ post procedure [27], [30]

In our study, the in-hospital cardiac death rate was less in the bivalirudin group as compared with the heparin group ( $1 \%$ vs. $4 \%$; $\mathrm{p}=0.366$ ). One cardiac death was also found in heparin groups in 30 days of PCI. Zhang et al. found similar results of death in a meta-analysis, where death was reported in $70 \mathrm{DM}$ patients assigned to the Bivalirudin and 92 patients assigned to the heparin group $(\mathrm{RR}=0.75 ; 95 \% \mathrm{CI} 0.56-1.02$; $\mathrm{p}=0.07$ ) [8]. Witzenbichler et al. have reported that the rates of cardiac death were significantly lower in diabetic STEMI patients who underwent primary PCI treated with bivalirudin compared with heparin plus GPI in 30 days of PCI (2.1\% vs. $5.5 \%, \mathrm{p}=0.04)$ [29]. 
There were several strengths of this study including randomization and there was no sponsor of this study. However, further multicenter large, randomized control trials would require evaluating the exact incidence of MACEs and hemorrhagic complications of bivalirudin in diabetic ACS patients undergoing PCI by comparing currently used three different anticoagulation strategies like bivalirudin, heparin plus GPI, and UHF monotherapy to generate evidence and future direction for Bangladeshi population.

\section{CONCLUSION}

In this small scale, prospective, randomized controlled study of diabetic ACS patients undergoing PCI in a single center showed that Bivalirudin is safe and effective as it reduces immediate and short-term hemorrhagic complications as well as major adverse cardiac events as compared with Heparin.

\section{REFERENCES}

[1] Cader, F.A., Haq, M.M., Nasrin, S. \& Kabir, C.M. 2017, Presentation, Management Practices and In-hospital Outcomes of Patients with Acute Coronary Syndrome in a tertiary Cardiac Centre in Bangladesh Bangladesh Heart Journal, vol.32, no.2, pp.106-13.

[2] Murray CJ, Lopez AD. Alternative projections of mortality and disability by cause 1990-2020: Global Burden of Disease Study. Lancet 1997; 349(9064):1498-504.

[3] Islam, A. \& Majumder, A. 2013, Coronary Artery Disease in Bangladesh, Indian Heart Journal, vol. 65, no.4, pp. 424-35.

[4] Libby P. Mechanisms of acute coronary syndromes and their implications for therapy. N Engl J Med. 2013; 368 (21):2004-13.

[5] Bagai A, Dangas GD, Stone GW, Granger CB. Reperfusion strategies in acute coronary syndromes. Circ Res. 2014; 114(12):1918-28.

[6] Lincoff, A.M., Bittl, J.A. \& Harrington, R.A. 2003, Bivalirudin and provisional glycoprotein IIb/IIIa blockade compared with heparin and planned glycoprotein IIb/IIIa blockade during the percutaneous coronary intervention: REPLACE-2 randomized trial' Journal of American Medical Association, vol.289, no.7, pp.853-63.

[7] Sohrabuzzaman APM, Zaman F, Mohammad N. 2017, Effect of Bivalirudin and Abciximab on myocardial necrosis in PCI patients, Bangladesh J Cardiol, 2017; 07 (01-02): 707-11

[8] Zhang, J. \& Yang, X. 2017, Efficacy and Safety of bivalirudin versus heparin in patients with diabetes mellitus undergoing percutaneous coronary intervention, Medicine (Baltimore) journal, vol. 96, no.29, pp. e7204.

[9] Gurm, H., Sarembock, I., Kereiakes, D., Young, J., Harrington, R., Kleiman, N.2005, Use of bivalirudin during percutaneous coronary intervention in patients with diabetes mellitus: An analysis from the Randomized Evaluation in Percutaneous Coronary Intervention Linking Angiomax to Reduced Clinical Events (REPLACE)-2 trial 'Journal of the American College of Cardiology, vol. 45, no.12, pp. 1932-38.

[10] Kastrati, A., Neumann, F.J. \& Schulz, S., 2011, Abciximab and heparin versus bivalirudin for non-ST-elevation myocardial infarction, New England Journal of Medicine, vol. 365, no.21, pp. 1980-89.

[11] Hirsh J, van Aken WG, Gallus AS, et al. Heparin kinetics in venous thrombosis and pulmonary embolism. Circulation.1976;53(4):691695.

[12] Young E, Prins M, Levine MN, Hirsh J. Heparin binding to plasma proteins, an important mechanism for heparin resistance. Thromb Haemost. 1992;67(6):639-643.

[13] Barzu T, Molho P, Tobelem G, et al. Binding and endocytosis of heparin by human endothelial cells in culture. Biochim Biophys Acta. 1985; 845 (2):196-203.

[14] Sobel M, McNeill PM, Carlson PL, et al. Heparin inhibition of von Willebrand factor-dependent platelet function in vitro and in vivo. $\mathrm{J}$ Clin Invest. 1991; 87(5):1787-1793.

[15] Hirsh J, Guyatt G, Albers GW, et al; American College of Chest Physician. Antithrombotic and thrombolytic therapy: American College of Chest Physicians Evidence-Based Clinical Practice Guidelines (8th Edition). Chest. 2008; 133(6 Suppl) :110S-112S.
[16] Lincoff, A.M., Califf, R.M. \& Topol, E.J. 2000, Platelet glycoprotein IIb/IIIa blockade in coronary artery disease', Journal of the American College of Cardiology, vol.35, no.5, pp.1103-115.

[17] Stone, G.W., White, H.D. \& Ohman, E.M. 2007, Bivalirudin in patients with acute coronary syndromes undergoing percutaneous coronary intervention: a subgroup analysis from the Acute Catheterization and Urgent Intervention Triage strategy (ACUITY) trial, The Lancet, vol. 369, no.9565, pp. 907-19.

[18] Stone, G.W., Witzenbichler, B. \& Guagliumi, G. 2008, Bivalirudin during primary PCI in acute myocardial infarction, New England Journal of Medicine, vol. 358, no.21, pp 2218-30.

[19] Han, Y., Guo, J. \& Zheng, Y.2015, Bivalirudin vs. heparin with or without tirofiban during primary percutaneous coronary intervention in acute myocardial infarction: the BRIGHT randomized clinical trial, Journal of American Medical Association, vol.313, no.13, pp.1336-46.

[20] Nairooz, R., Sardar, P. \& Amin, H., 2015. Short- and long-term outcomes in diabetes patients undergoing percutaneous coronary intervention with bivalirudin compared with heparin and glycoprotein IIb/IIIA inhibitors: a meta-analysis of randomized trials, Catheterization and Cardiovascular Intervention, vol.86, no.3, pp.36475.

[21] O'Gara PT, Kushner FG, Ascheim DD, et al. 2013 ACCF/AHA guideline for the management of ST-elevation myocardial infarction: a report of the American College of Cardiology Foundation/American Heart Association Task Force on Practice Guidelines. J Am Coll Cardiol. 2013;61: e78.

[22] Roffi M, Patrono C, Collet JP, et al. 2015 ESC guidelines for the management of acute coronary syndromes in patients presenting without persistent ST-segment elevation: Task Force for the Management of Acute Coronary Syndromes in Patients Presenting without Persistent ST-Segment Elevation of the European Society of Cardiology (ESC). Eur Heart J. 2016;37(3):267-315.

[23] Shahzad, A., Kemp, I. \& Mars, C.2014, Unfractionated heparin versus bivalirudin inprimary percutaneous coronary intervention (HEATPPCI): an open-label, single-center, randomized controlled trial Lancet, Vol.384, no.9957, pp.1849-58.

[24] Leonardi, S., Frigoli, E. \& Rothenbuhler, M. 2016, Bivalirudin or unfractionated heparin in patients with acute coronary syndromes managed invasively with and without ST elevation (MATRIX): randomized controlled trial, British Medical Journal, vol. 354, pp i4935.

[25] Thygesen K, Alpert JS, White HD, et al. for the Joint ESC/ACC/ AHA/WHF Task Force for the Redefinition of Myocardial Infarction Universal definition of myocardial infarction. Circulation. 2007; 116: $2634 \mathrm{e} 2653$.

[26] Laskey WK, Yancy CW, Maisel WH. Thrombosis in coronary drugeluting stents: a report from the meeting of the Circulatory System Medical Devices Advisory Panel of the Food and Drug Administration Center for Devices and Radiologic Health, December 7e8, 2006. Circulation. 2007; 115:2352e2357.

[27] Kaul, U., Dua, A. \& Sethi, A. K. 2015, Comparison of anti-thrombotic strategies using bivalirudin, Heparin plus Glycoprotein IIb/IIIa inhibitors, and Unfractionated Heparin Monotherapy for patients undergoing percutaneous coronary intervention-A single canter observational study' Indian Heart Journal, vol.67, no.4, pp. 311-17.

[28] Feit, F., Manoukian, S.V. \& Ebrahimi, R. 2008, Safety and Efficacy of Bivalirudin Monotherapy in Patients with Diabetes Mellitus and Acute Coronary Syndromes', Journal of the American College of Cardiology, vol.51, no. 17, pp.1645-52.

[29] Witzenbichler, B., Mehran, R., Guagliumi, G., Dudek, D., Huber, K., Kornowski, R.2011, Impact of diabetes mellitus on the safety and effectiveness of bivalirudin in patients with acute myocardial infarction undergoing primary angioplasty: analysis from the HORIZONS-AMI (Harmonizing Outcomes with RevasculariZatiON and Stents in Acute Myocardial Infarction), JACC: Cardiovascular Interventions, vol. 4, no.7, pp. 760-68.

[30] Steg PG, van't Hof A, Clemmensen P, et al. Design and methods of European Ambulance Acute Coronary Syndrome Angiography Trial (EURO MAX): an international randomized open-label ambulance trial of bivalirudin versus standard-of-care anticoagulation in patients with acute ST-segment elevation myocardial infarction transferred for primary percutaneous coronary intervention. Am Heart J. 2013 Dec; 166:960e967. 